\title{
26449 - MINIMUM EFFECTIVE DOSE OF REMIFENTANIL FOR PEDIATRIC LUMBAR PUNCTURE
}

\section{Jason Hayes MD, Mauro Arrica, MD; Alejandra Lopez, MD; James Robertson, Mark Crawford, MBBS; The Hospital For Sick Children, Toronto, ONTARIO, Canada}

INTRODUCTION: The administration of propofol for lumbar puncture (LP) is common in pediatric oncology patients. Propofol has no analgesic properties, and as a result patients often respond to the pain of LP needle insertion. Also, propofol may produce myoclonic movements that can make the procedure more difficult to perform. Remifentanil is an ultra-short acting opioid which can be used to provide analgesia and sedation for short painful procedures with minimal residual pain. The combination of propofol and remifentanil may be particularly suitable for short duration procedures. The purpose of this study was to determine the minimum effective dose of remifentanil required to prevent movement during LP when co-administered with propofol 2.0 or 4.0 $\mathrm{mg} / \mathrm{kg}$ (P2 or P4).

METHODS: After obtaining REB approval, 24 unpremedicated children aged 3-11 years undergoing elective LP have been studied to date. No topical anesthetic cream was applied to the skin over the lumbar region. Patients were randomly assigned to group P2 or P4 using a random number table. Anesthesia was induced with propofol followed immediately by remifentanil. The initial dose of remifentanil in each group was 1.0 $\mu \mathrm{g} / \mathrm{kg}$ in group P2 and $0.5 \mu \mathrm{g} / \mathrm{kg}$ in group P4. Subsequent doses of remifentanil were determined by the Dixon up-and-down method using a dose interval of $0.25 \mu \mathrm{g} / \mathrm{kg}$. 1 The LP needle was introduced at 90 seconds after propofol administration. Patients were given a rescue bolus of propofol $1.0 \mathrm{mg} / \mathrm{kg}$ if required. Occurrence of purposeful movement, duration of procedure, duration of apnea, and episodes of bradycardia or hypotension were recorded.

RESULTS: Patient age, weight, and duration of procedure are shown in the table. Using the Dixon up-and-down method, our preliminary data suggest that the minimum effective dose of remifentanil that prevents movement when co-administered with propofol 2.0 $\mathrm{mg} / \mathrm{kg}$ and $4.0 \mathrm{mg} / \mathrm{kg}$ is $1.00 \pm 0.19 \mu \mathrm{g} / \mathrm{kg}$ and $0.46 \pm 0.19 \mu \mathrm{g} / \mathrm{kg}$, respectively. The duration of apnea for patients who did not move was $56 \pm 21 \mathrm{~s}$ in group P2 and $49 \pm 38 \mathrm{~s}$ in group P4. There were no episodes of bradycardia or hypotension in either group. DISCUSSION: Preliminary data suggest that the administration of propofol and remifentanil provides effective anesthesia for pediatric patients undergoing LP. Minimum effective doses of remifentanil when used in combination with propofol 2 and $4 \mathrm{mg} / \mathrm{kg}$ are $1.00 \pm 0.19 \mu \mathrm{g} / \mathrm{kg}$ and $0.46 \pm 0.19 \mu \mathrm{g} / \mathrm{kg}$, respectively.

REFERENCES: 1. Statistics in Endocrinology. Cambridge, Massachusetts: MIT Press, 1970: 251-267. 


\begin{tabular}{|l|c|c|}
\hline & Propofol $2 \mathrm{mg} / \mathrm{kg}$ & Propofol 4 mg/g \\
\hline Age (yr) & $5.3 \pm 1.4$ & $5.2 \pm 2.7$ \\
\hline Weight (kg) & $19.1 \pm 4.4$ & $21.3 \pm 7.7$ \\
\hline Duration of procedure (s) & $222 \pm 42$ & $211 \pm 49$ \\
\hline $\begin{array}{l}\text { Minimman effective dose of } \\
\text { remifentanil (ugkg) }\end{array}$ & $1.00 \pm 0.19$ & $0.46 \pm 0.19$ \\
\hline Duration of apnea (s) & $56 \pm 21$ & $49 \pm 38$ \\
\hline
\end{tabular}

